\title{
Social Axioms of Young and Old People in India: A Survey Study
}

\author{
Ankita Singh $^{1 *}$, Shabana Bano ${ }^{2}$
}

\section{ABSTRACT}

Social axioms play a crucial role in the individual's belief and value systems. The major functions of axioms are to enhance the survival and functioning of people in their social environment. Leung and Bond (2004) proposed five dimensions of social axioms as social cynicism, social complexity, reward for application, fate control and religiosity. The present study was designed to examine the social axioms of younger and older people. The study was conducted with 86 participants ( $\mathrm{N}=51$ young and $\mathrm{N}=35$ old) age ranged 20-30 and 50-60 years. They were sampled from various areas of Varanasi City. The social axioms survey (Leung, Bond, Carrasquel, Munoz, Hernandez, Murikami, Yamagushi, Biebrauer\&Singelis, 2002) was administered to examine the participants. Result showed that older participants significantly higher on social cynicism, reward for application and religiosity than younger participants. With respect to social complexity and fate control, no significant difference was found. The findings suggest that social axioms are important to understand an individual's behaviour in a given society.

Keywords: Social Cynicism, Social Complexity, Reward For Application, Fate Control And Religiosity

We, human being, face a myriad of situations every day. Our behaviour is the reflection of these situations. Our behaviours are affected by our thought, rationale, emotion, values and beliefs particularly existing beliefs in the society. These beliefs transmitted from older generation to younger generation through socialisation. Although these beliefs are modified in the context of changing society. These beliefs are cognitive construct that help to understand behavioural differences among people. Katz (1960) define beliefs as the "description and perception of an object, its characteristics, and its relationship with other objects'. Beliefs are psychological variable help to understand the uniqueness of individual and their relation to the society. Leung, Bond, Carrasquel, Munoz, Hernandez, Murikami, Yamagushi, Biebrauer \& Singelis (2002) have proposed the study of general beliefs and developed the Social Axioms Survey (SAS) as a measure of such beliefs. The construct is termed "social axioms", defined as "generalized beliefs about oneself, the social and physical environment, or the spiritual world, and are in the

\footnotetext{
${ }^{1}$ Research Scholar, Department of Psychology, Banaras Hindu University, Varanasi, India

${ }^{2}$ Assistant Professor, Department of Psychology, Banaras Hindu University, Varanasi, India

*Responding Author

(c) 2016 I A Singh, S Bano; licensee IJIP. This is an Open Access Research distributed under the terms of the Creative Commons Attribution License (http://creativecommons.org/licenses/by/2.0), which permits unrestricted use, distribution, and reproduction in any Medium, provided the original work is properly cited.
} 


\section{Social Axioms of Young and Old People in India: A Survey Study}

form of an assertion about the relationship between two entities or concepts'. These are beliefs held by persons about the world in which they function, and as such constitute personalized measures of the social situation they confront.

Based on multicultural studies in 41 countries, Leung and Bond (2004) have identified fivefactor structure of social axioms at the individual level, namely Social Cynicism, Social Complexity, Reward for Application, Religiosity, and Fate Control. Social cynicism refers to a negative view of human nature, a biased view against some groups of people, a mistrust of social institutions, and a disregard of ethical means of achieving an end. Social complexity refers to beliefs that there are no rigid rules but rather multiple ways of achieving a given outcome and that inconsistency in human behavior is common. Reward for Application is a general belief that effort, knowledge, and careful planning will lead to positive results. Religiosity refers to belief in the existence of supernatural forces and the functions of religious belief. Fate Control is a belief that life events are predetermined and that there are some ways to influence these outcomes.

According to Leung et al. (2002), social axioms serve at least four functions: (a) valueexpressiveness: presenting one's values, (b) knowledge: helping people understand the world, (c) instrumentality: facilitating attainment of important goals, and (d) ego-defensiveness: protecting self-worth. Social axioms serve as general knowledge about the world, such that they function as governing principles for beliefs in different specific domains. In line with this argument, social axioms predict attitudinal variables in many areas of psychological investigation, such as political attitudes (Keung \& Bond, 2002) paranormal beliefs (Singelis, Hubbard, Her, \&An, 2003), vocational interests (Bond, Leung, Au, Tong, \& Chemonges-Nielson, 2004), and attitudes towards help-seeking (Kuo, Kwantes, Towson, \& Nanson, 2006). Importantly, social axioms do have survival utility. A study done by Kurman and Ronen-Eilon (2004) suggested that immigrants adapt better if they have accurate knowledge about social axioms characterizing their host cultures. Thus, social axioms serve as a set of important psychological tools helping individuals to comprehend, relate to, and even maneuver in the social world.

Social axioms also serve as guiding principles steering progress towards the attainment of important goals in life. This belief reflects how a means is related to a specific end and the subjective judgment of the likelihood with which a particular means leads to a particular end in a given situation (Vroom, 1964). Accordingly, different social axioms might pair up a given end with different prescribed means. For example, reward for application defines the contingency between effort invested and reward received, whereas social cynicism defines the contingency between one's social power and probable reward. More specifically, in a conflict situation, reward for application predicts preference for collaborative and compromising strategies to reach a better decision, while social cynicism predicts a competitive orientation, which involves an exercise of power or defense against its probable use by a collaborator (Bond et al., 2004; Chen \& Zhang, 2004). Similarly, reward for application predicts preference for using persuasive influence tactics, while social cynicism predicts assertive and relationship-based tactics, which are again exercises in power and status advantage (Fu, Kennedy, Tata, Yukl, Bond, Peng, 2004). 
Therefore, social axioms govern choices, their generation and selections, leading to situation ally based goal attainment as selected by the "belief-holder." Social axioms have important implications for our self-worth and subjective well-being. Social axioms define instrumentality of various means to reach a given goal, they should predict how individuals cope with the challenges of life and achieve self-worth and well-being. For example, reward for application predicts the use of a problem-solving coping style, while fate control predicts passive forms of coping, namely wishful thinking and distancing (Bond et al., 2004). Although self-worth and well-being are universal goals, it is important to note that individual differences exist in assessing the effectiveness of different strategies. For example, individuals high in social cynicism exhibited more negative attitudes towards seeking help through professional services (Kuo et al., 2006). This result may serve as one of the factors accounting for the robust finding that social cynicism is consistently linked to a more gloomy psychological condition, such as low life dissatisfaction (Chen, Cheung, Bond, \& Leung, 2006; Lai, Bond, \& Hui, 2007), psychological distress (Kuo et al., 2006), and death ideation (Hui, Bond, \& Ng, 2007).

Every generation thinks that the previous and the next generation are vastly different from theirs. In reality, they share same hopes, feelings, attitude, understanding and fears that their older generations held. We want a clean, peaceful and prosperous world. Did our older generation want something different? Does our coming generation want something different? Even today, with technology being so easy to accessible, the new generation still wants what we wanted, what our older generation always wanted namely to make meaningful relationships with people around them and give and seek friendship, love, attention and approval in a social context. This is the basic human nature and universal longing, but in this rapidly metamorphosing society these beliefs, too, are under duress of change. The present generation is also in a transition period where they keep their valuable culture, beliefs, customs and tradition and maintain their uniqueness with that. Some studies are found in health psychology (Dutta \& Basu, 2007), educational psychology (Holloway, Kashiwagi, Hess, \& Azuma, 1986; Wingert, 1998), clinical psychology (Kanofsky \& Lieb, 2007), and family psychology (Snarey \& Dollahite, 2001; Soenens et al., 2005). In social psychology, studies on the intergenerational beliefs and values are sparse. With respect to social axioms, no study has been done in order to assess intergeneration gap in India. Thus, the present study is an attempt to find out the pattern of social axioms of old and young generations in Indian culture.

\section{Objective:}

- To examine the various dimensions of social axioms of young and old people.

\section{Method}

The study was conducted with 86 participants ( $\mathrm{N}=51$ young and $\mathrm{N}=35$ old) age ranged 20-30 and 50-60 years. They were sampled from Varanasi City. The following tools were employed to examine the pattern of social axioms of old and young participants:

Demographic schedule: The schedule consisted personal detail of participants including: age, gender, marital status, educational level, occupation, income, residence, family structure and language known. 
Social axioms scale: It was developed by Leung, Bond, Carrasquel, Munoz, Hernandez, Murikami, Yamagushi, Biebrauer \& Singelis (2002). This scale was used to examine the dimensions of social axioms of the participants. It consists of 69 items related to five dimensions of social axioms. The alpha values of these dimensions are: Social Cynicism (.82), Reward for Application (.75), Social Complexity (.74), Fate Control (.59) and Religiosity (.49).

The participants were contacted individually to getting their consent. Before the administration of the Social axioms scale, the participants were briefed about the purpose of the study. Selfadministered Social axioms scale was used to examine the participants. After getting the consent of the participants the aforesaid tool was administered as per the standard instructions of the Social axioms scale. All participants were requested to respond to each items of the scale. Participants were ensured about the maintenance of their anonymity and confidentiality.

\section{RESULTS:}

Table: Shows mean, SD and Significance of difference between the scores of young and old participants on social axioms measure.

\begin{tabular}{|c|c|c|c|c|}
\hline \multicolumn{2}{|c|}{ Dimensions of social axioms } & \multirow{2}{*}{$\begin{array}{l}\text { Young } \\
61.29\end{array}$} & \multirow{2}{*}{$\begin{array}{l}\text { Old } \\
69.68\end{array}$} & \multirow{3}{*}{\begin{tabular}{|l} 
t value \\
$3.725^{* *}$
\end{tabular}} \\
\hline \multirow{2}{*}{ Social cynicism } & Mean & & & \\
\hline & SD & 10.06 & 11.719 & \\
\hline \multirow{2}{*}{ Social complexity } & Mean & 53.52 & 55.48 & \multirow{2}{*}{1.346} \\
\hline & SD & 8.014 & 5.480 & \\
\hline \multirow{2}{*}{ Reward for application } & Mean & 67.61 & 70.51 & \multirow{2}{*}{$2.656^{* *}$} \\
\hline & SD & 6.208 & 6.203 & \\
\hline \multirow{2}{*}{ Fate control } & Mean & 24.49 & 26.42 & \multirow{2}{*}{1.743} \\
\hline & SD & 5.520 & 4.860 & \\
\hline \multirow{2}{*}{ Religiosity } & Mean & 42.64 & 45.54 & \multirow{2}{*}{$2.610^{* *}$} \\
\hline & SD & 5.836 & 4.773 & \\
\hline
\end{tabular}

Table shows mean, SD and Significance of difference between the scores of young and old people on social axioms measure. It revealed significant difference between young and old participants on these dimensions of axioms as social cynicism ( $\mathrm{t}=-3.725, \mathrm{p}<.01$ ), reward for application (2.656, $\mathrm{p}<.01$ ) and religiosity $(2.610, \mathrm{p}<.01)$. With respect to social complexity and fate control, no significant difference was found. The findings reported generational differences, suggesting that old generation showed more concern to all the dimensions of axioms in comparison to young generation as social cynicism (mean=69.68>61.29), reward for application 
(mean=70.51>67.61), religiosity (mean=45.54>42.64) social complexity (mean=55.48>53.52) and fate control (mean=26.42>24.49).

\section{DISCUSSION:}

The present study examines the pattern of social axioms of young and old generation. The findings of present study revealed that old generation endorsed more social cynicism, reward for application, religiosity, social complexity and fate control as compared to young people. It suggests that older people believe in negative aspect of human nature, groups and other things than young people. This may be explained that the older people do not have much more desires and hopes for future especially in Indian culture where the people at this age generally prepare themselves for their last journey of life (i. e., death). While the younger people look at the positive side of society and larger world as they have lot of wishes to be fulfil in the future.

Our findings reported that older people believe in fate as well as reward for application in comparison to younger. This is because of Indian philosophical thought as stated in ShlokSaitalish, Adhyay- Dvitiya, Shrimad Bhagavad Gita Yatharoop that "karma hi puja hai" (work is worship), "karma karophalkichinta mat karo" (do work without expecting about the outcome) suggesting that old people are more intrinsically oriented (to enjoy process not the outcome) rather than young people, they have more concern about outcome. Boehnke (2009) found that for social cynicism, mothers had lower scores than both fathers and offspring. For reward for application, medium levels of structural intergenerational similarity was found. In the case of fate control and social complexity, young generation endorsed this social axiom more highly rather than the parent generation. Both students and mothers differed significantly from fathers, who endorsed religious beliefs least on religiosity. Another study (Oceja, 2009) also reported that on the dimension of fate control and religiosity, young people scored lower than adults whereas young people scored higher than adults on social complexity and reward for application. For social cynicism did not found any significant result. The effect of context (i.e. related vs. non-related) was not found significant. Ghosh (2009) found in her study that reward for application was the strongest belief for the college student group and also found a significant effect of gender on the fate control.

The findings of the present study has shown contradiction from the previous studies. This may be due to cultural differences as Indian society is basically collectivistic and also found individualistic orientations. People in this culture learn their values, beliefs, traditions, customs, courage, self-respect, honesty, trust, integrity, humor, empathy, and respect to others from their elders. Today, the world is changing rapidly due to technology development and globalization. Now, we are the part of global village and adopting both collectivistic and individualistic orientations. Therefore, the existing belief of our society changes and the reflection of these changes are more in young generation in comparison to old generation.

Studies conducted on social axioms shows the endorsement of these beliefs in other cultures Hong-Kong, Venezuela, United States, Japan and Germany (Leung et al., 2002) also. This 
studies shows predictive ability of social axioms toward a variety of behaviours and received some recent attention (e.g. Bond, et al., 2004; Neto, 2006; Safdar, Lewis, \& Daneshpour, 2006; Malham \& Saucier 2014). Relation of social axioms dimensions with other variables (i.e., values) revealed that social axioms added moderate predictive power over and above that provided by values to vocational choices, methods of conflict resolution, and coping styles (Bond et al., 2004). They found that reward for application predicts better coping and adjustment and social complexity facilitates coping and adjustment in intercultural contact. Fate control and religiosity was found to be positively correlated with interpersonal harmony and self-esteem (Safdar, et. al. 2006). Singelis, et al., (2003) have also found that belief in reward for application correlated with maintaining good relations with others.

Thus, findings of the present study reported intergenerational changes with respect to the endorsement of social axioms. The endorsement of all five dimensions of social axioms was higher among old people as compared to young. It suggests that social axioms can be helpful to understand the social behaviour of people belonging to different generations in a particular cultural context as the axioms are reflection of the cultural notion.

\section{REFERENCES:}

Boehnke, K. (2009). Are parents decisive? The intergenerational transmission of social axioms under conditions of rapid social change. In K. Leung \& M. H. Bond (Eds.), Psychological Aspects of Social Axioms: Understanding global belief systems (pp. 109-127). New York: Springer Science.

Bond, M. H., Leung, K., Au, A., Tong, K., \& Chemonges-Nielson, Z. (2004).Combining social axioms with values in predicting social behaviors. European Journal of Personality, 18 (3), 177-191.

Chen, L., \& Zhang J. (2004).Relation between general social beliefs and interpersonal conflict resolution styles. Chinese Journal of Clinical Psychology, 12, 151-153.

Chen, S. X., Cheung, F. M., Bond, M. H., \& Leung, J. P. (2006).Going beyond self-esteem to predict life satisfaction: The Chinese case. Asian Journal of Social Psychology, 9, 24-35.

Dutta, M. J., \& Basu, A. (2007). Health among men in rural Bengal: Exploring meanings through a culture-centered approach. Qualitative Health Research, 17 (1), 38-48.

Fu, P. P., Kennedy, J., Tata, J., Yukl, G., Bond, M. H., \& Peng, T. K., (2004). The impact of societal cultural values and individual social beliefs on the perceived effectiveness of managerial influence strategies: A meso approach. Journal of International Business Studies, 35, 284-305.

Ghosh, A. (2009). Social axioms and individualistic-collectivist orientations in Indian college students. In K. Leung \& M. H. Bond (Eds.), Psychological Aspects of Social Axioms: Understanding global belief systems (pp. 283-292). New York: Springer Science.

Holloway, S. D., Kashiwagi, K., Hess, R. D., \& Azuma, H. (1986).Causal attributions by Japanese and American mothers about performance in mathematics. International Journal ofPsychology, 21, 269-286.

Hui, V. K. Y., Bond, M. H., \& Ng, T. S. W. (2007). General beliefs about the world as defensive mechanisms against death anxiety.Omega, 54, 199-214.

Kanofsky, S., \& Lieb, R. J. (2007). Control mastery theory and family therapy. Psychotherapy: Theory, Research, Practice, Training, 44 (3), 316-332. 


\section{Social Axioms of Young and Old People in India: A Survey Study}

Katz, D. (1960) “The functional approach to the study of attitudes”. Public Opinion Quarterly, 24, 163-204.

Keung, D. K. Y., \& Bond, M. H. (2002).Dimensions of political attitudes and their relations with beliefs and values in Hong Kong. Journal of Psychology in Chinese Societies, 3, 133154.

Kuo, B. C. H., Kwantes, C. T., Towson, S., \& Nanson, K. M. (2006). Social beliefs as determinants of attitudes toward seeking professional psychological help among ethnically diverse university students. Canadian Journal of Counselling, 40, 224-241.

Kurman, J., \& Ronen-Eilon, C. (2004).Lack of knowledge of a culture's social axioms and adaptation difficulties among immigrants. Journal of Cross-Cultural Psychology, 35, 192-208.

Lai, J. H., Bond, M. H., \& Hui, N. H. (2007). The role of social axioms in predicting life satisfaction: A longitudinal study in Hong Kong. Journal of Happiness Studies, 8, 517535.

Leung, K., \& Bond, M. (2004). Social axioms: A model for social beliefs in multicultural perspective. Advances in Experimental Social Psychology, 36, 119-197.

Leung, K., Bond, M. H., De Carrasquel, S. R., Munoz, C., Hernandez, M., Murakami, F., Yamaguchi, S., Bierbrauer, G., \& Singelis, T. M. (2002). Social axioms: The search for universal dimensions of general beliefs about how the world functions. Journal of crosscultural psychology, 33, 286-302.

Malham, P. B., \& Saucier, G. (2014). Measurement invariance of social axioms in 23 countries. Journal of cross cultural psychology, 45 (7), 1046-1060.

Neto, F. (2006).Dimensions and correlates of Social axioms among a Portuguese sample. Individual Differences Research, 4, 340-351.

Oceja, L. (2009). Processes of transmission and change of social sxioms and their behavioral influence in Spanish culture. In K. Leung \& M. H. Bond (Eds.), Psychological Aspects of Social Axioms: Understanding global belief systems (pp. 128-141). New York: Springer Science.

Safdar, S., Lewis, J. R. \& Daneshpour, M. (2006). Social axioms in Iran and Canada: Intercultural contact, coping and adjustment. Asian Journal of Social Psychology, 9, 123-131.

Singelis, T. M., Hubbard, C., Her, P., \& An, S. (2003). Convergent validation of the social axioms survey. Personality and Individual Differences, 34, 269-282.

Snarey, J. R., \& Dollahite, D. C. (2001). Varieties of religion-family linkage: A commentary. Journal of Family Psychology, 15, 646-651.

Soenens, B., Elliot, A. J., Goossens, L., Vansteenkiste, M., Luyten, P., \& Duriez, B. (2005). The intergenerational transmission of perfectionism: Parents' psychological control as intervening variable. Journal of Family Psychology, 19(3), 358-366.

Swami Prabhupad, S. S. A. C. B. Shrimad Bhagavad Gita Yatharoop. Bhakti Vedant Book Trust: Hare Krishna Dham, Juhu, Mumbai, 1975.

Vroom, V. H. (1964). Work and Motivation. New York: Wiley.

Wingert, H. D. (1998). The label "gifted": Parent beliefs, transmission of beliefs and impact on the child. Dissertation Abstracts International Section A: Humanities and Social Sciences,59(1-A), 0340.

How to cite this article: A Singh, S Bano (2016), Social Axioms of Young and Old People in India: A Survey Study, International Journal of Indian Psychology, Volume 3, Issue 3, No. 8, DIP: 18.01.149/20160303, ISBN: 978-1-365-12176-0 